Research Article

\title{
Study of efficacy of oral ivermectin in comparison to commonly used topical antiscabetic drugs gamma benzene hexachloride and permethrin
}

\author{
Suman Kanwar*, Sunil K. Mathur, Sanjay Sankhla
}

\author{
Jawaharlal Nehru Medical \\ College, Ajmer, Rajasthan, India \\ Received: 27 June 2016 \\ Revised: 30 June 2016 \\ Accepted: 02 July 2016

\section{*Correspondence to: \\ Dr. Suman Kanwar, \\ Email: sumankanwar81@ \\ gmail.com}

Copyright: (C) the author(s), publisher and licensee Medip Academy. This is an openaccess article distributed under the terms of the Creative Commons Attribution NonCommercial License, which permits unrestricted noncommercial use, distribution, and reproduction in any medium, provided the original work is properly cited.

\begin{abstract}
Background: Scabies is an infectious disease, contagious in nature and caused by Sarcoptes Scabiei, is transmitted readily, often throughout an entire household, by prolonged skin-to-skin contact with an infected person. The objective was to know the efficacy of oral ivermectin in the treatment of scabies infection in comparison to commonly used topical antiscabetic drugs gamma benzene hexachloride and permethrin.

Methods: Using prospective, longitudinal, comparative randomized design, study was conducted for a period of one year in 299 patients, in the age group of 5 to 60 years, belonging to both sexes, attending outpatient department of dermatology of J.L.N. Medical College and associated hospitals Ajmer (RAJ), India. Pregnant and lactating women, children below 5 years, elderly patients more than 60 year, patients not willing to come for follow-up and patients with any serious systemic illness were excluded. Data so collected, were analyzed as per the aims and objectives with the help of appropriate statistical software (primer statistical software version 6).

Results: Efficacy of oral ivermectin therapy was comparable with topical permethrin therapy but more efficacious (statistically significant) than topical gama benzene hexachloride therapy.

Conclusions: Ivermectin can be a very useful weapon in patients who do not show compliance with topical therapy.
\end{abstract}

Keywords: Scabies, Ivermectin, Permethrin, Gama benzene hexachloride, Oral, Topical

\section{INTRODUCTION}

Scabies is a neglected parasitic disease that is a major public health problem in many resource-poor regions. Scabies is an infectious disease, contagious in nature and caused by Sarcoptes scabiei (it has got another name acarus) is transmitted readily, often throughout an entire household, by prolonged skin-to-skin contact with an infected person. ${ }^{1}$

Symptoms of scabies infestation include rash and intense pruritus that is often worse at night. The lesions begin as tiny erythematous papules and can progress to vesicles or pustules. Linear burrows are a classic feature but are not seen commonly. Excoriation and ulceration also may be present, and a more generalized hypersensitivity reaction, including urticaria, may occur. In severe cases and in immunocompromised hosts, large areas of crusting may be seen. Although outbreaks can occur almost anywhere, the axillae, web spaces between fingers, and flexor surfaces of the wrists are the most common areas. Male genitalia, female breasts, the gluteal crease, waistband, and antecubital fossae also are frequently affected. The face and scalp usually are spared except in infants. ${ }^{2}$

Prevention is based on limitation of contact with the mite. This implies early diagnosis and adequate treatment. Various topical pharmaceutical preparations are said to be effective in the treatment (cure) of infestation with scabies. These include: sulphur compounds; benzyl benzoate, crotamiton, hexachlorocyclohexane (also known as gamma benzene hexachloride or the 
commercial purified form lindane) malathion and permethrin.

Disease control requires treatment of the affected individual and all people they have been in contact with, but is often hampered by inappropriate or delayed diagnosis, poor treatment compliance and improper use of topical compounds such as permethrin, lindane or benzyl benzoate. Oral ivermectin is an effective and costcomparable alternative to topical agents in the treatment of scabies infection. It may be particularly useful in the treatment of severely crusted scabies lesions in immune compromised patients or when topical therapy has failed. Oral dosing may be more convenient in institutional outbreaks and in the treatment of mentally impaired patients. The safety of oral ivermectin in pregnant and lactating women and young children has yet to be established.

Hence it was decided to study and compare three antiscabetics-the most commonly used topical antiscabetic-gamma benzene hexachloride, permethrin, and oral ivermectin. The objective of the study was to know the efficacy of oral ivermectin in comparison to commonly used topical antiscabetic drugs gamma benzene hexachloride and permethrin.

\section{METHODS}

This was a prospective, longitudinal, comparative randomized study conducted in patients attending outpatient department of dermatology of J.L.N. Medical College and associated hospitals Ajmer (Rajasthan), India. 306 patients, in the age group of 5 to 60 years, belonging to both sexes were included in the study after taking consent. The duration of the study was one year; from August 2013 to July 2014. Pregnant and lactating women, children below 5 years, elderly patients more than 60 year, patients not willing to come for follow-up and patients with any serious systemic illness were excluded from the study.

Patients were allocated randomly into three groups i.e. group I, group II and group III. (102 patients in each group).

Group I: Patients were given single dose of oral ivermectin $200 \mu \mathrm{g} / \mathrm{kg}$ body weight.

Group II: Patients were given topical permethrin 5\%.

Group III: Patients were given topical gamma benzene hexachloride $1 \%$. Both Permethrin and gamma benzene hexachloride should be applied topically after scrub bath and left overnight.

The patients were followed at $1^{\text {st }}$ week and $6^{\text {th }}$ week. A careful history of the patient was taken. Participants were advised not to use or mix any other treatment, including antipruritic or antihistaminic medicines.
Parameters used to study the efficacy of the regimens:

- Severity of the disease

- Itching

Severity of the disease is measured according to the number of lesions present. It can be graded as;

- Mild (grade-I): <10 lesions

- Moderate (grade-II): 11-49 lesions

- $\quad$ Severe (grade-III): >50 lesions

Severity of itching is evaluated by visual analogues scale (VAS). VAS is defined as a $10 \mathrm{~cm}$ line, in which point 0 refers to existence of no pruitus and point 10 refers to the most severe pruritus. According to this scale, we scored pruritus of the patients.

Point 1 to 3: Mild pruritus (grade-I)

Point 4 to 6: Moderate pruritus (grade-II)

Point 7 to 10: Severe pruritus (grade-III)

Pre-structured proforma was used to collect the relevant information (patients data, clinical finding etc) at baseline, $1^{\text {st }}$ week and $6^{\text {th }}$ week of follow-up.

\section{RESULTS}

Out of 306 patients 7 were dropped out during follow up, 3 from group-I, 2 from group-II \& III each, so total 299 patients were evaluated at the end of study. Table 1 shows age \& sex incidence of scabies. Most of the patients (35\%) belong to the age group of 11-20 years followed by 21-30 years who constituted to $27 \%$ of scabies.

Table 1: Age and sex incidence.

\begin{tabular}{|lllll|}
\hline \multirow{2}{*}{ Age } & \multicolumn{2}{l}{ No. of patients } & & Percentage \\
& Male & Female & Total & \\
\hline $6-10$ & 30 & 14 & 44 & 14.71 \\
\hline $11-20$ & 63 & 39 & 102 & 35.17 \\
\hline $21-30$ & 49 & 31 & 80 & 26.755 \\
\hline $31-40$ & 20 & 30 & 50 & 16.72 \\
\hline $41-50$ & 10 & 8 & 18 & 6.02 \\
\hline $51-60$ & 3 & 2 & 5 & 1.67 \\
\hline Total & $\mathbf{1 7 5}$ & $\mathbf{1 2 4}$ & $\mathbf{2 9 9}$ & $\mathbf{1 0 0}$ \\
\hline
\end{tabular}

Table 2 shows occupational status of patients. Out of 299 patients, majority were students who constituted to $38 \%$ (114) followed by daily wagers and agriculturists $23 \%$ (69) and 14\% (42) respectively.

Table 3 shows family history of scabies and it was positive in $73 \%$ of patients. Table 4 shows that in the present study nocturnal itching was present in $98 \%$ of patients.

Table 5 shows location of lesion in scabies patients. In present study interdigital space and flexor aspect of wrist 
were involved in $90.63 \%$ of the patients followed by, genitalia, and medial aspect of thigh in $60.20 \%$ and $50.16 \%$ respectively.

Table 2: Occupational status of patients.

\begin{tabular}{|lll|}
\hline Occupation & No. of cases & Percentage \\
\hline Students & 114 & 38.12 \\
\hline Agriculturists & 42 & 14.05 \\
\hline House wives & 32 & 10.7 \\
\hline Service class & 27 & 9.03 \\
\hline Daily wagers & 69 & 23.08 \\
\hline Business man & 3 & 1 \\
\hline Others & 12 & 4.01 \\
\hline Total & $\mathbf{2 9 9}$ & $\mathbf{1 0 0}$ \\
\hline
\end{tabular}

Table 3: Family history.

\begin{tabular}{|lll|}
\hline Family history & No. of patients & Percentage \\
\hline Present & 219 & 73.24 \\
\hline Absent & 80 & 26.76 \\
\hline Total & 299 & 100 \\
\hline
\end{tabular}

Table 4: Nocturnal itching.

\begin{tabular}{|lll|}
\hline Nocturnal Itching & No. of patients & Percentage \\
\hline Present & 292 & 97.65 \\
\hline Absent & 7 & 2.35 \\
\hline Total & 299 & 100 \\
\hline
\end{tabular}

Table 6 shows type of lesions. In the present study 181 $(90.8 \%)$ patients had papular lesions and $172(86 \%)$ had vesicular lesions, $103(51.8 \%)$ had pustules and excoriations were found in $119(59.5 \%)$ of the patients.

Table 5: Locations of lesion.

\begin{tabular}{|ll|l|}
\hline Site of lesion & No.of patients & Percentage \\
\hline $\begin{array}{l}\text { Inter digital space and } \\
\text { flexor aspect of wrist }\end{array}$ & 271 & 90.63 \\
\hline Lower abdomen & 141 & 47.15 \\
\hline Fore arm & 116 & 38.79 \\
\hline Axillary folds & 90 & 30.1 \\
\hline Genitalia & 180 & 60.2 \\
\hline Thighs (medial aspect) & 150 & 50.16 \\
\hline Gluteal region & 28 & 9.36 \\
\hline
\end{tabular}

Table 6: Type of lesions.

\begin{tabular}{|lll|}
\hline Type of lesions & No. of patients & Percentage \\
\hline Papules & 270 & 90.5 \\
\hline Vesicles & 257 & 86 \\
\hline Nodules & 03 & 01 \\
\hline Pustules & 177 & 59.5 \\
\hline Eczematization & 110 & 37 \\
\hline Excoriations & 153 & 51.5 \\
\hline Crusts & 7 & 2.5 \\
\hline Others & 22 & 7.5 \\
\hline
\end{tabular}

Table 7 shows comparison of results among three Groups at the end of 6 weeks considering severity of itching and severity of the disease as a parameter of efficacy. Efficacy of group-I and group-II were statistically significant as compared with group-III.

Table 7: Comparison of results of various regimens at the end of 6 weeks.

\begin{tabular}{|c|c|c|c|c|c|}
\hline \multirow[t]{2}{*}{ Regimens } & \multirow[t]{2}{*}{ No .of pts. } & \multicolumn{2}{|c|}{ Itching at 6 weeks } & \multicolumn{2}{|c|}{ Severity of lesion at 6 weeks } \\
\hline & & Improved (\%) & $\begin{array}{l}\text { Not improved } \\
(\%)\end{array}$ & Improved (\%) & $\begin{array}{l}\text { Not improved } \\
(\%)\end{array}$ \\
\hline I- Ivermectin & 99 & $75(75.75 \%)$ & $24(24.24 \%)$ & $77(77.77 \%)$ & $22(22.22 \%)$ \\
\hline II- Permethrin & 100 & $78(78 \%)$ & $22(22 \%)$ & $77(77 \%)$ & $23(23 \%)$ \\
\hline III-Gamabenzenehexachloride & 100 & $58(58 \%)$ & $42(42 \%)$ & $59(59 \%)$ & $41(41 \%)$ \\
\hline \multicolumn{2}{|l|}{ Chi-square test } & \multicolumn{2}{|c|}{$\mathrm{X}^{2}=11.707 ; \mathrm{P}=0.0029 \mathrm{p}<.05,(\mathrm{~s})$} & \multicolumn{2}{|c|}{$\mathrm{X}^{2}=11.182 ; \mathrm{P}=0.0037 \mathrm{p}<.05,(\mathrm{~s})$} \\
\hline \multirow{3}{*}{$\begin{array}{l}\text { Difference between groups } \\
\text { (p-values) }\end{array}$} & I-II & \multicolumn{2}{|l|}{$\mathrm{P}=0.8666,(\mathrm{~ns})$} & \multicolumn{2}{|c|}{$\mathrm{P}=0.8655,(\mathrm{~ns})$} \\
\hline & I-III & \multicolumn{2}{|l|}{$\mathrm{P}=0.0106,(\mathrm{~s})$} & \multicolumn{2}{|l|}{$\mathrm{P}=0.0061,(\mathrm{~s})$} \\
\hline & II-III & \multicolumn{2}{|l|}{$\mathrm{P}=0.0040,(\mathrm{~s})$} & \multicolumn{2}{|l|}{$\mathrm{P}=0.0100,(\mathrm{~s})$} \\
\hline
\end{tabular}

n- significant, ns- non-significant

\section{DISCUSSION}

\section{Age and sex distribution and occupational status}

In present study most of the patients $(50 \%)$ were in the age group of 6-20 years whereas $27 \%$ of the patients were in the age group of 21-30 years. Thus scabies was found to be more common in children and young adults. Similar results were also found in others studies by Sehgal et al,
Gulati et al and Nair et al. ${ }^{1-3}$ Incidence of scabies was found more among males as compared to females. Nair et al, Hati et al, Sehgal et al, have also observed male preponderance in their studies. ${ }^{1,2,4}$ Further, higher incidence of scabies $(38.12 \%)$ found in students in this study. The higher incidence in children and young adults can attributable to the fact, that intermingling is common among children whereas higher incidence among students is due to multiple causes like playing together in the 
school, living together in hostels and the habit of using the dresses and linen of the friends, which add to the transmission of the disease in them. Male preponderance is attributable to the more chances of exposure.

\section{Family history}

Family history of scabies was found positive in $73.24 \%$ of patients. Such higher incidence of family history in the patients of scabies was also reported by Usha et al in their study on two groups treated with either ivermectin or permethrin, who had a positive family were $82.5 \%$ and $55.6 \%$ respectively.

The higher incidence of family history among the affected depicts the capacity of scabies to spread among close contacts and stresses the need for treatment of all the contacts.

\section{Nocturnal itching}

Nocturnal itching was present in $97.65 \%$ of patients. Nair et al, found nocturnal itching in $89 \%$ of the patients. ${ }^{6}$ Thus, nocturnal itching may be a helpful information in making the diagnosis, especially in the absence of facilities for demonstrating the mite.

\section{Location of lesions}

In present study interdigital space and flexor aspect of wrist were involved in $90.63 \%$ of the patients followed by, genitalia and medial aspect of thigh in $60.20 \%$ and $50.16 \%$ respectively. Lesions on lower abdomen were present in $47.15 \%$ patients. Desai et al have observed the involvement of hands and wrists in $84.8 \%$ of their cases. Thus, location of lesion can be a useful clinical indicator.

However in the present study involvement of genitalia was seen in $60.20 \%$ whereas Desai et al and Hati et al, observed genital involvement only in $36 \%$ and $23.8 \%$ of cases respectively. ${ }^{7,4}$ Regarding the involvement of other sites like axillae and buttocks, the different authors have observed variable percentage of involvement in their studies.

\section{Type of lesions}

In the present study $90.8 \%$ patients had papular lesions and $86 \%$ had vesicular lesions. Jackson et al, found papular lesions most commonly in scabies patients. Usha et al, found that $25 \%$ of patients out 40 patients treated with ivermectin had secondary infection. ${ }^{8,5}$ The secondary infection (pustules) in this study $(59.5 \%)$ was more compared to $(25 \%)$ in Usha et al study.

This may be because of the low education level, overcrowding, unhygienic condition, lack of awareness in our patients compared to Kerala were the study was conducted by Usha et al. ${ }^{5}$

\section{Response to treatment in various regimens}

\section{Oral ivermectin (200 $\mu \mathrm{g} / \mathrm{kg}$ body weight, single dose)}

Oral ivermectin given as single dose $(200 \mu \mathrm{g} / \mathrm{kg}$ body weight) in patients of scabies. Out of 99 patients considering the itching as the parameter, 52 (52.52\%) patients improved at 2 weeks and $23(23.23 \%)$ between 2nd-6th week. Total number of patients showing after complete subsidence at 6 th week was $75(75.75 \%)$.

Similarly considering severity of lesion as the parameter in 99 patients, improvement was seen in $63(63.63 \%)$ and $14(14.14 \%)$ at 2 nd and between 2 nd-6th week. Total number of patients who showed improvement was $77(77.77 \%)$

Usha et al, found that a single dose of ivermectin provided a cure rate of $70 \%$, which increased to $95 \%$ with 2 doses at a 2 week interval. Meinking et al, reported $100 \%$ clearance with single oral dose of ivermectin in 11 patients with uncomplicated scabies. ${ }^{5,9}$ Chouela et al, found the cure rate of scabies at 15 th day, after treatment with ivermectin single dose of $(150-200 \mu \mathrm{g} / \mathrm{kg})$ to be $74 \%{ }^{10}$

\section{Topical permethrin 5\% lotion (single application)}

Out of 100 patients treated with $5 \%$ permethrin lotion cure was seen in $56 \%$ and $22 \%$ at $2^{\text {nd }}$ week and between 2nd-6th weeks respectively .Total number of patients cured at 6 th week was $78 \%$.

Considerably the severity of lesion, number of patients cured was $62 \%$ and $15 \%$ at 2 nd week and between 2 nd6 th weeks respectively. Total number of patients cured at 6 th week was $77 \%$.

Zargari et al, and Taplin et al, have found a cure rate of $84.6 \%$ and $43 \%$ respectively after 2 weeks of therapy. ${ }^{11,12}$ Similarly Hegary et al and Usha et al found permethrin to be effective as a single application with cure rate of $84.9 \%$ and $97.8 \%$ respectively. ${ }^{13,5}$

\section{Topical GBHC $1 \%$ lotion (single application)}

Out of 100 patients in the present study with itching as the parameter, improvement with GBHC $1 \%$ lotion was seen in $39 \%$ and $19 \%$ of the patients at 2 nd week and between 2nd-6th weeks respectively. Total improvement was seen in $58 \%$ patients.

Considering severity of lesion as the parameter, improvement was seen in $49 \%$ and $10 \%$ of patients at 2 nd week and between 2 nd and 6 th week respectively. Total improvement was seen in $59 \%$ patients. Taplin et al, Zargari $\mathrm{M}$ et al, Chouela et al, have found $65 \%, 48.9 \%$, $44.44 \%$, $54 \%$ cure rate respectively with $1 \%$ lindane lotion after 1 month. ${ }^{10-12,14}$ 


\section{Comparison of statistical significance among three groups}

Difference in efficacy of group I (ivermectin) therapy was statistically non-significant with group II (permethrin) but statistically significant with group III (gama benzene hexachloride). This shows that efficacy of group I therapy was comparable to group II therapy but more efficacious than group III therapy. Group II therapy was more efficacious than group III because difference in efficacy was statistically significant. Thus the finding of present study has statistical validation between groups.

Although topical agents carried certain drawbacks, present study reported that single application of permethrin $5 \%$ gave maximum response when severity of itching and severity of lesion were taken as parameters to compare efficacy of different groups thus making it the most effective treatment and therefore suitable to be the treatment of choice.

Response to single oral dose of ivermectin $200 \mu \mathrm{g} / \mathrm{kg}$ body weight was slightly low when compared to topical permethrin but higher when compared to response obtained with topical GBHC. Though the results obtained with single oral dose of ivermectin $(200 \mu \mathrm{g} / \mathrm{kg}$ body weight) in patients belonging to group 1 were slightly low compared to permethrin, patient acceptance was very good especially among students living in hostels, where inadequate facilities for bathing and taking a good scrub bath were the major hurdle in topical application.

Despite the need for further exploration, oral ivermectin could be a viable alternative for management of scabies especially where compliance to topical scabicides is improbable or impractical.

A significant reduction in disease burden is possible only when along with appropriate scabicides, treatment of all contacts and clothings are done simultaneously and the underlying environmental and social conditions that promote infectious skin diseases are addressed. Improvement in literacy and economic status along with awareness about personal hygiene can definitely bring down the prevalence of this disease.

Funding: No funding sources Conflict of interest: None declared

Ethical approval: The study was approved by the Institutional Ethics Committee

\section{REFERENCES}

1. Sehgal VN. Scabies-epidemiology and ecology. Indian J Dermatol Verenereol Leprol. 1997;43:2669.

2. Gulati PV, Sachder TR, Varma RK. Scabies-an epidemiological study in a resettlement colony. Indian J Dermatol Verenereol Leprol. 1981;47(6):299-302.

3. Nair BKH, Joseph A, Narayan. Epidemiology of scabies. Indian J Dermatol Verenereol Leprol. 1973;39:101-5.

4. Hati AK, Chaudhary DSR, Gupta R. Clinico parasitological studies on scabies. J Dermatol Vereneol. 1974;:40:3-4.

5. Usha V, Nair GK. A comparative study of oral ivermectin and topical permethrin cream in the treatment of scabies. J Am Acad Dermatol. 2000;4:1521-4.

6. Nair BK, Joseph A, Kandamutham M. Epidemic scabies. Indian J Med Res. 1977;65(4):513-8.

7. Deasi SC, Nair SS. Ecological and epidemiological study of scabies in India. Indian $\mathbf{J}$ Dermatol Verenereol Leprol. 1977;49:210-2.

8. Jackson A, Heukelback J, Filho AF, Junior Ede B, Feldmeier $H$. Clinical features and associated morbidity of scabies in a rural community in Alagoas, Brazil. Trop Med Int Health. 2007;12(4):493-502.

9. Meinking TL, Taplin D, Hermida JL, Pardo R, Kerdel FA. The treatment with ivermectin. N Engl J Med. 1995;333:26-30.

10. Chouela EN, Abeldano AM, Pellerano G, Paple RM, Garsd A. Equivalent therapeutic efficacy and safety of ivermectin and lindane in the treatment of human scabies. Arch Dermatol. 1999;135:651-5.

11. Taplin D, Meinking TL, Porcelain SL, Castillero PM, Chen JA. Permethrin 5\% dermal cream: a new treatment for scabies. J Am Acad Dermatol. 1986;15:991-1001.

12. Zargori O, Golchai J, Sobhani A, Dehpour AR, Sadr AS, Alizadeh N. Comparison of the efficacy of topical $1 \%$ lindane vs $5 \%$ permethrinin scabies : a randomized, double-blind study. Indian J Dermatol Verenereol Leprol. 2006;72(1):33-6.

13. Hegazy AA, Darwish NM, Ibrahim A, Hamid A, Hammad SM. Epidemiology and control of scabies in a Egyptian village. Int J Dermatol. 1999;38:291-5.

14. Madan V, Jaskiran K, Gupta U, Gupta DK. Oral ivermectin comparison with $1 \%$ topical lindane lotion. Int J Dermatol. 2001;28:481-4.

Cite this article as: Kanwar S, Mathur SK, Sankhla

S. Study of efficacy of oral ivermectin in comparison to commonly used topical antiscabetic drugs gamma benzene hexachloride and permethrin. Int J Basic Clin Pharmacol 2016;5:1234-8. 